\title{
Idiopathic pulmonary haemosiderosis with allergic pulmonary vasculitis
}

\author{
LEOPOLD BUERGER AND JAMES HATHAWAY
}

From the Department of Pathology, Ohio State University, Columbus, Ohio, U.S.A.

During the past decade an increasing number of cases of idiopathic pulmonary haemosiderosis have been reported. The clinical findings and symptomatology of this disease have become so well recognized that it is frequently diagnosed ante mortem. Despite an increasing knowledge of the clinical aspects of this disorder, its aetiology remains obscure. Certain morphological features encountered in the present case merit description because they suggest an allergic aetiology.

\section{CASE HISTORY}

A white housewife aged 46 years was admitted to the Lockbourne Air Force Base Hospital, Columbus, Ohio, with a history of haemoptysis, dyspnoea, and non-pleuritic pain in the right chest posteriorly for the past three to four weeks. She had had two episodes of haemoptysis, 18 and nine years before admission, both of which necessitated bronchoscopy. In each instance no source of bleeding was found. Physical examination revealed no cyanosis or clubbing of the digits. The lungs were normal to percussion and auscultation. Chest radiography showed bilateral perihilar infiltration. The temperature was $100^{\circ} \mathrm{F}$.

She had a leucocytosis of 10,650 with $5 \%$ eosinophils, a haemoglobin of $10.4 \mathrm{~g}$. per $100 \mathrm{ml}$. and haematocrit of $30 \%$. The blood urea nitrogen, serum protein, serum calcium, and phosphate concentrations were within normal limits. Sputum cultures and studies for acid-fast bacilli were negative.

On the fourth day in hospital the patient developed a spiking fever and slight dyspnoea. She then experienced a haemoptysis of $250 \mathrm{ml}$. of bright red blood after which she became dyspnoeic, tachypnoeic, and cyanotic. The haemoglobin dropped to $8.3 \mathrm{~g}$. per $100 \mathrm{ml}$. Treatment with oxygen, intermittent positive pressure breathing, blood transfusions, streptomycin, lanatoside c (cedilanid), and later hydrocortisone failed to improve her condition. She died in severe dyspnoea on the eleventh day in hospital. The clinical diagnosis was possible pulmonary haemosiderosis.

NECROPSY Both lungs were heavy (right $950 \mathrm{~g}$., left $900 \mathrm{~g}$.) and on cross section all lobes showed haemor- rhagic consolidation (Fig. 1). There was no evidence of pulmonary vessel sclerosis or other anomalies, and the heart did not show right ventricular hypertrophy. The hilar lymph nodes were slightly enlarged and pinkish-brown on cross section.

HISTOPATHOLOGY The alveoli were filled to varying degrees with erythrocytes and haemosiderin-laden macrophages that stained intensely for iron. Occasionally, the alveolar surfaces were covered by a membrane of fibrin in a manner reminiscent of hyaline membrane disease of the newborn. Fragmentation of the elastic fibres with iron incrustation and fibrosis was encountered in the alveolar septa and in the small to medium sized pulmonary arteries and arterioles.

In the interstitial tissue giant cells of the foreign body type with phagocytosed fragments of elastic fibres (Figs. 2A and 2B) were present in addition to deposits of iron. The capillaries and arterioles were engorged with blood. The endothelial cells were swollen and showed evidence of proliferation. Marked perivascular oedema, the presence of eosinophils, and diapedesis of erythrocytes (Figs. 3A and 3B) were noted. Rarely, fibrin thrombi were present in arterioles and capillaries. The stomach was the only other organ in which identical vascular changes were found.

\section{DISCUSSION}

Early investigators of idiopathic pulmonary haemosiderosis (I.P.H.) were impressed by the degeneration and disruption of elastic fibres, the foreign body giant cell reaction, and the accumulation of iron. These findings were interpreted as evidence of constitutionally inferior lung tissue by Glanzmann and Walthard (1941), and more specifically of defective development of elastic fibres by von Moellendorff (1952). The possibility that I.P.H. is a hereditary disorder was raised by Glanzmann and Walthard (1941). However, the evidence for this has not been well documented, and this notion has been largely rejected.

The aetiological significance of the pathological changes in the elastic fibres has been questioned by Wyllie, Sheldon, Bodian and Barlow (1948) and 




FIG. 1. Right and left lung with haemorrhagic consolidation, subpleural and on cross section.

by Joseph, Job and Gentil (1957), who found that in fulminant cases of I.P.H. alterations of the elastica were not present. In addition, Lendrum, Scott, and Park (1950) have pointed out that similar, though less severe, alterations of elastic fibres are frequently encountered in lungs affected by long-standing passive congestion, especially in cases of mitral stenosis. Propst (1955) and Doering and Gothe (1957) emphasized that the deposition of iron pigment is secondary to changes in the elastic fibres.

Numerous investigators have proved that the disease is not related to a primary haemolytic disturbance (Propst, 1955; Apt, Pollycove and Ross, 1957 ; Frick, Brunner, Gasser and Hitzig, 1962) or to a defect in iron metabolism (Propst, 1955 ; Doering and Gothe, 1957 ; Frick et al., 1962). Clinically, the not uncommon association of I.P.H. with allergic manifestations, such as purpura (Edge and Waind, 1959; MacGregor, Johnson and Turk, 1960), glomerulonephritis (Heptinstall and Salmon, 1959 ; MacGregor et al., 1960), arthritis, and the Schönlein-Henoch syndrome, has aroused interest in the possibility that I.P.H. may have an allergic basis. The common denominator in all of the conditions associated with I.P.H. is a vasculitis which may be exudative, necrotizing, or proliferative, depending on the acuteness, severity, and duration of the inflammation.

These clinical and pathological features have given rise to the following pertinent question: Is I.P.H. primarily an angiitis (Anspach, 1939 ; Edge and Waind, 1959 ; MacGregor et al., 1960)? Is the 3 angiitis allergic (MacGregor et al., 1960 ; Frick et al., 1962)? Lastly, is I.P.H. a pulmonary variety of the Schönlein-Henoch syndrome (Zollinger and Hegglin, 1958; Bürger, 1960)? An angiitis has been found to represent the basic alteration in $a \frac{D}{0}$ variety of allergic conditions of the respiratory tract. In this regard, pulmonary allergic granuloma $N$ and Wegener's granuloma are of particular interest $N$ since both conditions may be associated with 유 extrapulmonary angiitis (Spencer, 1962 ; Godman ${ }^{\omega}$ and Churg, 1954); thus they resemble I.P.H. The allergic pulmonary angiitis associated with I.P.H. remains to be adequately documented. With the exception of the report by Zollinger and Hegglin ${ }^{-}$ (1958), we are not aware of any literature dealing with this relationship.

The histopathological findings in the present $\frac{\odot}{\Phi}$ case suggest that I.P.H. is an allergic disease which is characterized primarily by an allergic vasculitis. What relation I.P.H. bears to that spectrum of $\delta$ 

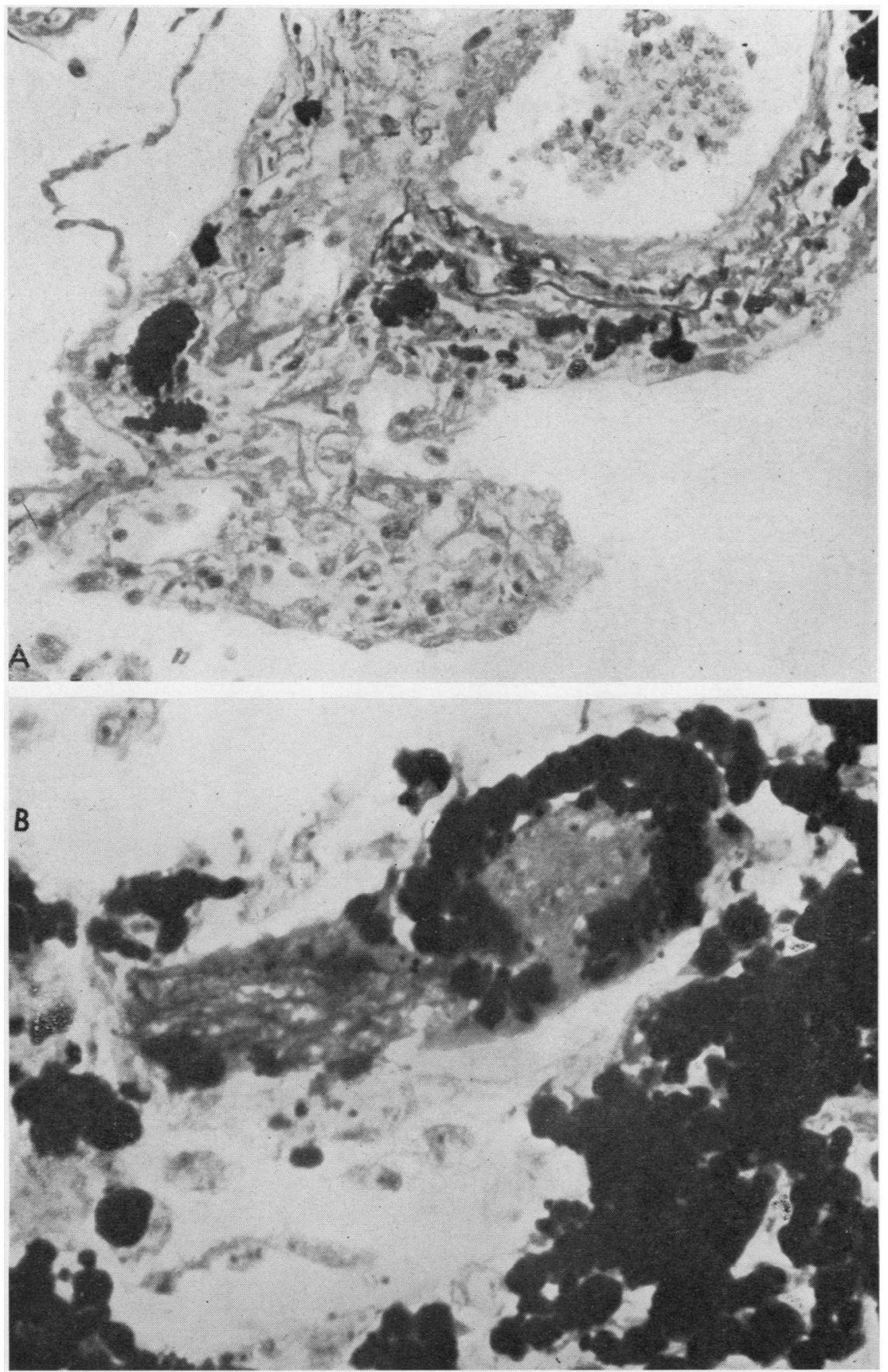

FIG. 2. (A) Iron deposition in interstitial lung tissue and fragmentation of vascular elastic fibres with iron incrustation. Gomori iron stain and Verhoeff's elastic stain, $\times 380$. (B) Interstitial lung tissue with elastic fibre fragments and giant cell reaction. Iron deposition. Gomori iron stain and Verhoeff's elastic stain, $\times 700$. 

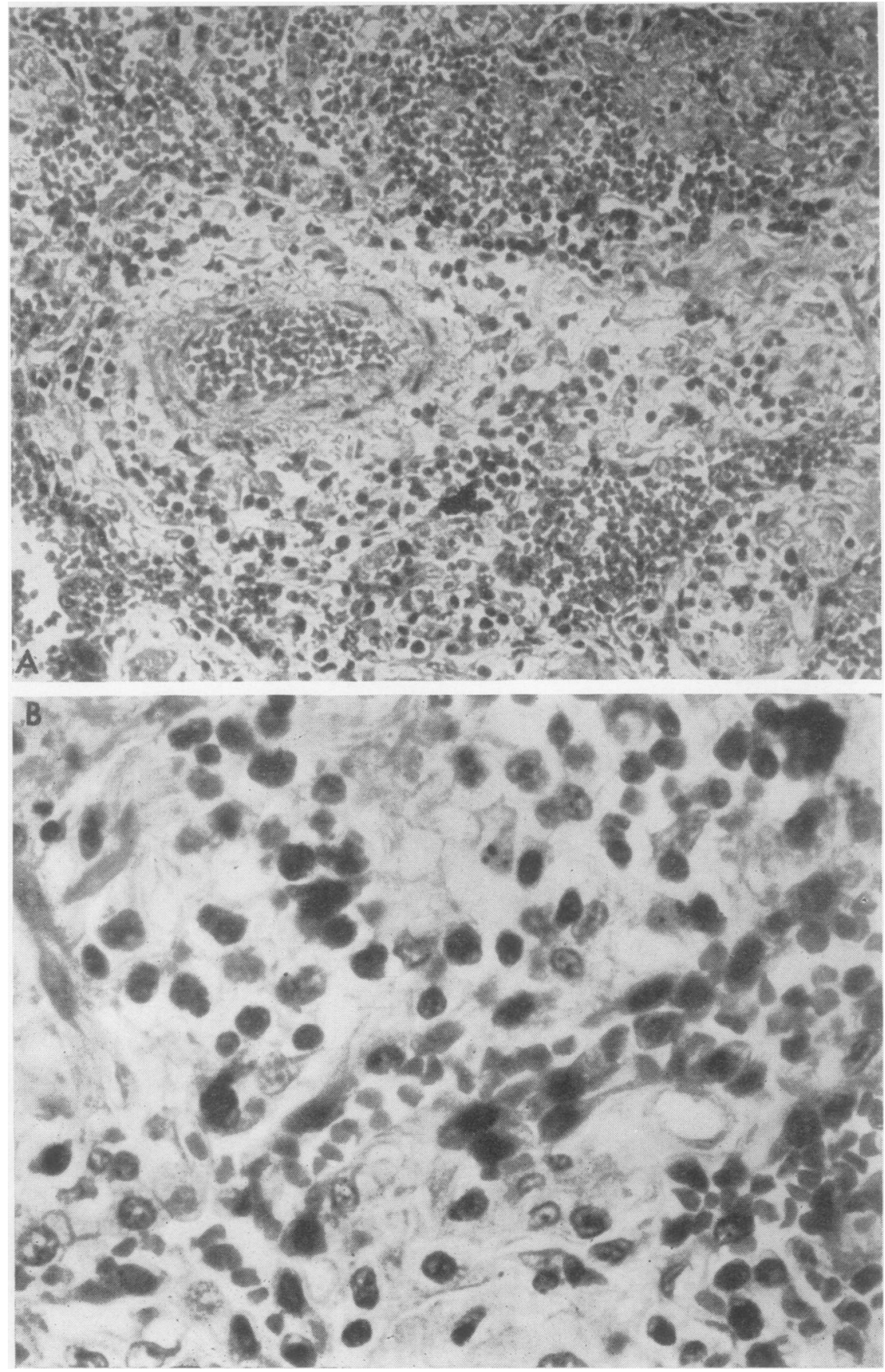

FIG. 3. (A) Recent haemorrhage and interstitial oedema with capillaritis in lung with fulminant idiopathic pulmonary haemosiderosis. Haematoxylin and eosin, $\times 280$. (B) Pulmonary interstitial capillaritis with perivascular oedema and cellular, predominantly eosinophilic infiltration. Haematoxylin and eosin, $\times 650$. 
clinical entities associated with allergic vasculitis, which include the Schönlein-Henoch syndrome (Gairdner, 1948), peliosis rheumatica, anaphylactoid purpura, and haemorrhagic capillary toxicosis, remains to be clarified.

The lack of morphological support of allergic vasculitis as the primary lesion of I.P.H. may be attributed to the following factors: I.P.H. is a rare disorder and is often characterized by a protracted course with cor pulmonale and recurrent massive pulmonary haemorrhage. The lung tissue in these cases is so altered by the secondary changes of haemosiderosis and fibrosis that the arteriolar and capillary pathology is masked. Diagnostic lung biopsies (Spencer, 1962) performed in suspected cases of I.P.H. may confirm the allergic vasculitis which we believe characterizes the early stages of this disease. It may be that biopsies performed during periods of peripheral eosinophilia would be more enlightening in this respect.

\section{SUMMARY}

The case of a 46-year-old woman with idiopathic pulmonary haemosiderosis is described. At necropsy an acute, aseptic pulmonary vasculitis was found, and an allergic aetiology of the disorder is suggested.

The authors wish to thank Dr. Stephen Ockner, Captain, U.S.A.F., who made it possible for us to study this case ; and Dr. Dante G. Scarpelli, Associate Professor and Chief, Division of Teaching and
Research, Department of Pathology, Ohio State University, for valuable discussion and advice.

\section{REFERENCES}

Anspach, W. E. (1939). Pulmonary hemosiderosis. Amer. J. Roentgenol., 41, 592.

Apt. L., Pollycove, M., and Ross, J. F. (1957). Idiopathic pulmonary hemosiderosis. A study of the anemia and iron distribution using radioiron and radiochromium. J. clin. Invest., 36, 1150.

Bürger, L. (1960). Schönlein-Henochsche Erkrankung mit gleichzeitigen dermatomyositisähnlichen Veränderungen und ihre Stellung zu den Kollagenosen. Zb. allg. Path. path. Anat., 101, 176.

Doering, P., and Gothe, H. D. (1957). Die idiopathische Lungenhämosiderose, klinische Beobachtungen und radiologische Untersuchungen mit Eisen bei einem 17-jährigen Patienten. Klin. Wschr., 35, 1105.

Edge, J. R., and Waind, A. P. B. (1959). Idiopathic pulmonary haemosiderosis in an adult. Thorax 14,85 .

Frick, P. G., Brunner, H. E., Gasser, C., and Hitzig, W. H. (1962). Eisenstoffwechsel und Erythrocytenkinetik bei idiopathischer Lungenhämosiderose. (Untersuchungen mit $\mathrm{Fe}^{\mathrm{sg}}$ und $\mathrm{Cr}^{51}$.) Schweiz. med. Wschr., 92, 1307.

Gairdner, D. (1948). The Schönlein-Henoch syndrome (anaphylactoid purpura). Quart. J. Med., 17, 95.

Glanzmann, E., and Walthard, B. (1941). Idiopathische progressive braune Lungeninduration im Kindesalter. Mschr. Kinderheilk., 88, 1.

Godman, G. C., and Churg, J. (1954). Wegener's granulomatosis. Pathology and review of the literature. Arch. Path., 58, 533 .

Heptinstall, R. H., and Salmon, M. V. (1959). Pulmonary haemorrhage with extensive glomerular disease of the kidney. J. clin. Path. 12, 272

Hirrle, W. (1952). U ber sogenannte essentielle braune Lungeninduration. Frankfurt. Z. Path., 63, 329.

Joseph, R., Job, J. C., and Gentil, C. (1957). L'hémosidérose pulmonaire idiopathique. Arch. franc. Pediat., 14, 36.

Lendrum, A. C., Scott, L.D. W., and Park, S. D. S. (1950). Pulmonary changes due to cardiac disease with special reference to haemosiderosis. Quart. J. Med., 19, 249.

MacGregor, C. S., Johnson, R. S., and Turk, K. A. D. (1960). Fatal nephritis complicating idiopathic pulmonary haemosiderosis in young adults. Thorax, 15, 198.

Moellendorff, von, cited by Hirrle, W. (1952). Uber sogenannte essentielle braune Lungeninduration. Frankfurt. Z. Path., 63, 329.

Propst, A. (1955). Morphologie und Pathogenese der essentiellen Lungenhämosiderose. Virchows Arch. path. Anat., 326, 633.

Spencer, H. (1962). Pathology of the Lung, p. 523. Pergamon, Oxford.

Wyllie, W. G., Sheldon, W., Bodian, M., and Barlow, A. (1948). Idiopathic pulmonary haemosiderosis (essential brown induration Idiopathic pulmonary haemosiderosis (ess
of the lungs). Quart. J. Med., 17, 25 .

Zollinger, H. U., and Hegglin, R. (1958). Die idiopathische Lungenhämosiderose als pulmonale Form der Purpura SchönleinHenoch. Schweiz. med. Wschr., 88. 439. 